\title{
Factors predicting coroners' decisions to hold discretionary inquests
}

\author{
Simon J. Walter LLB BSc, Lyndal Bugeja PhD, Matthew J. Spittal PhD, David M. Studdert LLB ScD
}

\begin{abstract}
- Abstract
Background: Coroners in Australia, Canada, New Zealand and other countries in the Commonwealth hold inquests into deaths in two situations. Mandatory inquests are held when statutory rules dictate they must be; discretionary inquests are held based on the decisions of individual coroners. Little is known as to how and why coroners select particular deaths for discretionary inquests.
\end{abstract}

Methods: We analyzed the deaths investigated by Australian coroners for a period of seven and one-half years in five jurisdictions. We classified inquests as mandatory or discretionary. After excluding mandatory inquests, we used logistic regression analysis to identify the factors associated with coroners' decisions to hold discretionary inquests.

Results: Of 20379 reported deaths due to external causes, 1252 (6.1\%) proceeded to inquest.
Of these inquests, 490 (39.1\%) were mandatory and 696 (55.6\%) were discretionary. In unadjusted analyses, the rates of discretionary inquests varied widely in terms of age of the decedent and cause of death. In adjusted analyses, the odds of discretionary inquests declined with the age of the decedent; the odds were highest for children (odds ratio [OR] 2.17, 95\% confidence interval $[\mathrm{Cl}]$ 1.54-3.06) and lowest for people aged 65 years and older (OR 0.38, $95 \% \mathrm{Cl}$ 0.28-0.51). Using poisoning as a reference cause of death, the odds of discretionary inquests were highest for fatal complications of medical care (OR 12.83, 95\% Cl 8.65-19.04) and lowest for suicides (OR $0.44,95 \% \mathrm{Cl} 0.30-0.65$ ).

Interpretation: Deaths that coroners choose to take to inquest differ systematically from those they do not. Although this vetting process is invisible, it may influence the public's understanding of safety risks, fatal injury and death.
I n Anglo-American legal systems, coroners operate as an inquisitorial branch of the judiciary, investigating the cause and circumstances of deaths reported to them. ${ }^{1,2}$ For most of the deaths investigated, coroners' findings follow an administrative review of documentary evidence, including reports of postmortem examinations, police reports and witness statements. ${ }^{2}$ However, a small selection of cases proceed to an inquest - formal public hearings in which witnesses testify and parties connected to the death may retain lawyers. Many inquests draw public attention and coverage by media. ${ }^{3}$ They are arguably the most visible aspect of the work of coroners.

For coroners in Australia, Canada, New Zealand and many other countries in the Commonwealth, inquests are held for two main reasons. Statutes governing coroners' courts dictate that inquests must be held in certain specified circumstances (mandatory inquests). For cases that fall outside the mandatory criteria, coroners may choose to hold an inquest (discretionary inquests). A great deal of variation in the rates of inquests is evident between and within countries (Table 1). ${ }^{1,46}$

The vetting process for determining which cases are subject to a discretionary inquest is invisible, but it may influence the public's understanding of risks, fatal injuries and untimely death. As such, profiling which cases are selected for such inquests is valuable. Furthermore, because the investigations and recommendations generated by inquests are the centrepiece of the coroner's role in preventing untimely deaths, the vetting process can shape their contribution to public health and safety.

We examined the characteristics of discretionary inquests to determine whether these cases differed systematically from those resolved through administrative investigations.

\section{Methods}

\section{Setting}

Coroners' courts in Australia are state-based. Reporting requirements vary slightly across the six states and two territories. In general, a coro-
Competing interests:

Lyndal Bugeja is employed with the Coroners Court of

Victoria. No other competing interests were declared.

This article has been peer reviewed.

Correspondence to:

David Studdert,

d.studdert@unimelb.edu.au

CMAJ 2012. DOI:10.1503

/cmaj.110865 
ner must be notified of a death if it was violent or unexpected, if the identity of the decedent is not known, or if the decedent was in the custody or care of the state when he or she died. ${ }^{1,2,7}$

The governing legislation in all jurisdictions ${ }^{8-14}$ sets forth specific rules for mandatory inquests and confers broad powers to hold discretionary inquests. One exception is the Australian Capital Territory (ACT), ${ }^{15}$ where mandatory inquests dominate. The standard trigger for mandatory inquests is a death that occurs in prison or police custody, or while the decedent is in the care of the state for reasons of serious mental or physical illness. The policy rationale for these statutory rules is the serious concern automatically raised by deaths under these circumstances. ${ }^{1}$

By contrast, discretionary inquests are not restricted to particular circumstances; they can be held into any death (other than those meeting the criteria for mandatory inquests) if a coroner believes an inquest is desirable..$^{8-14}$ With 18000 reported deaths each year, Australian coroners must be highly selective as to which are chosen for discretionary inquests.

\section{Data}

Our primary source of data was the National Coroners Information System (NCIS), an electronic system for data storage and retrieval containing information on deaths investigated by

Table 1: Rates of coroners' inquests in selected jurisdictions of Australia, the United Kingdom, New Zealand, the Republic of Ireland and Canada*

\begin{tabular}{|c|c|}
\hline Jurisdiction and period & $\begin{array}{l}\text { Inquests per } 1000 \\
\text { reported deaths, no. }\end{array}$ \\
\hline \multicolumn{2}{|l|}{ Australia† } \\
\hline New South Wales 2000-2007 & 49 \\
\hline Victoria 2000-2007 & 45 \\
\hline Queensland 2001-2007 & 50 \\
\hline Western Australia 2000-2007 & 42 \\
\hline \multicolumn{2}{|l|}{ United Kingdom } \\
\hline England and Wales $2000-2007^{4}$ & 122 \\
\hline Scotland $2001 \neq$ & 5 \\
\hline Northern Ireland 2001 & 54 \\
\hline New Zealand 2001 & 286 \\
\hline Republic of Ireland 2001 & 185 \\
\hline \multicolumn{2}{|l|}{ Canada } \\
\hline Ontario 2001 & 4 \\
\hline British Columbia $2002-2007^{5,6}$ & 2 \\
\hline \multicolumn{2}{|c|}{$\begin{array}{l}\text { *Unless otherwise stated, rates are adapted from data presented in the Luce report." } \\
\text { tRates in all Australian jurisdictions calculated directly from data in the National Coroners } \\
\text { Information System. } \\
\text { fProcurators Fiscal perform an analogous role to coroners in Scotland; according to the Luce } \\
\text { report, the deaths reported to and investigated by them are "comparable to the range } \\
\text { handled in many coronial systems." }\end{array}$} \\
\hline
\end{tabular}

Australian coroners. ${ }^{16}$ The NCIS comprises a standardized set of coded and free text fields, including the text of the coroner's findings. ${ }^{17}$ The information comes directly from coroners' courts in each state and territory, which regularly upload the relevant data from their own electronic casemanagement systems. ${ }^{17}$ Examinations of the quality of the data in the NCIS suggest that it reliably captures information on reportable deaths..$^{18,19}$

This study was approved by the ethics committee at the Department of Justice, Victoria, Australia.

\section{Study sample}

Coroners in all six Australian states and the two territories have uploaded death reports to the NCIS since July 1, 2000, with the exception of Queensland, which began on Jan. 1, 2001. Because investigations can take two or more years to complete, we chose Dec. 31, 2007, as our cut-off date for death reports.

Cases from the ACT and Western Australia were excluded from our analyses. Coroners in the ACT have limited discretion over whether to hold inquests, and accessing identifying information on Western Australian cases requires separate ethics approval, which we did not seek. In addition, two of the remaining states were missing data for several years, so these years were excluded from our analyses (see Appendix 1, available at www.cmaj.ca/lookup/suppl/doi:10 .1503/cmaj.110865/-/DC1). Our final dataset included 20379 deaths with external causes, taken from reports to coroners covering 30.5 state-years (Northern Territory 2000-2007, Queensland 2006-2007, South Australia 2002-2007, Tasmania 2000-2007 and Victoria 2000-2007).

\section{Classification of inquests as mandatory or discretionary}

Although the focus of our study was discretionary inquests, the NCIS does not record whether inquests were mandatory or discretionary. Two investigators (Simon Walter and Lyndal Bugeja) reviewed the text of the findings associated with all inquests in the sample to determine which were mandatory. This determination was straightforward for some cases because coroners explicitly stated in their findings what prompted the inquest (e.g., as required by legislation or through exercise of their discretion). For cases not including this information, an inquest's status as mandatory or discretionary was determined by reviewing the circumstances of the death in light of the jurisdiction's rules governing mandatory inquests. To test the reliability of these judgments, a random subsample of 65 inquests underwent blinded review by both 
reviewers. Interrater reliability was excellent (94\% agreement, $\kappa=0.88 ; 95 \%$ confidence interval [CI] 0.76-0.99).

\section{Predictors}

We classified cause of death into nine categories, adapted from those used in the NCIS: intentional self-harm; transport-related; poisoning; drowning, choking and suffocation; falls; assault; complications of medical care; other; and not known. Details of how these categories were created are available in Appendix 1. We also extracted the sex, age and marital and employment status of the decedent. In addition, we thought that the socioeconomic status of the decedent might affect the probability of a discretionary inquest being held. Because the NCIS does not include variables indicating socioeconomic status, we merged our data with the "socioeconomic indexes for areas" (SEIFA scores) developed by the Australian Bureau of Statistics, linking them to the residential postal code of each decedent. SEIFA scores were then converted to quintiles for analysis. Details of the SEIFA measures are available in Appendix 1.

\section{Statistical analysis}

Removing mandatory inquests left a pool of cases resolved by either discretionary inquest or by administrative investigations. We calculated counts and proportions for the variables of interest. We also used univariable and multivariable logistic regression analyses to identify significant predictors of discretionary inquests. The dependent variable in the regression analysis was binary, distinguishing cases that went to discretionary inquest from those that were resolved with administrative investigations.

There were six independent variables in the multivariable model: sex, age, marital status, socioeconomic status, employment status and cause of death, although employment status was dropped from the final model owing to collinearity with age and marital status. Our model also controlled for jurisdiction (state or territory), year and their interaction. Tests for goodness of $\mathrm{fit}^{20}$ and outlier observations supported our model's validity.

\section{Results}

\section{Characteristics of the sample}

Among 20379 deaths due to external causes, $1252(6.1 \%)$ proceeded to inquest (Figure 1). Of these inquests, $696(55.6 \%)$ were held at the coroner's discretion, 490 (39.1\%) were mandatory and $66(5.3 \%)$ could not be classified because their findings had not been uploaded to the NCIS.

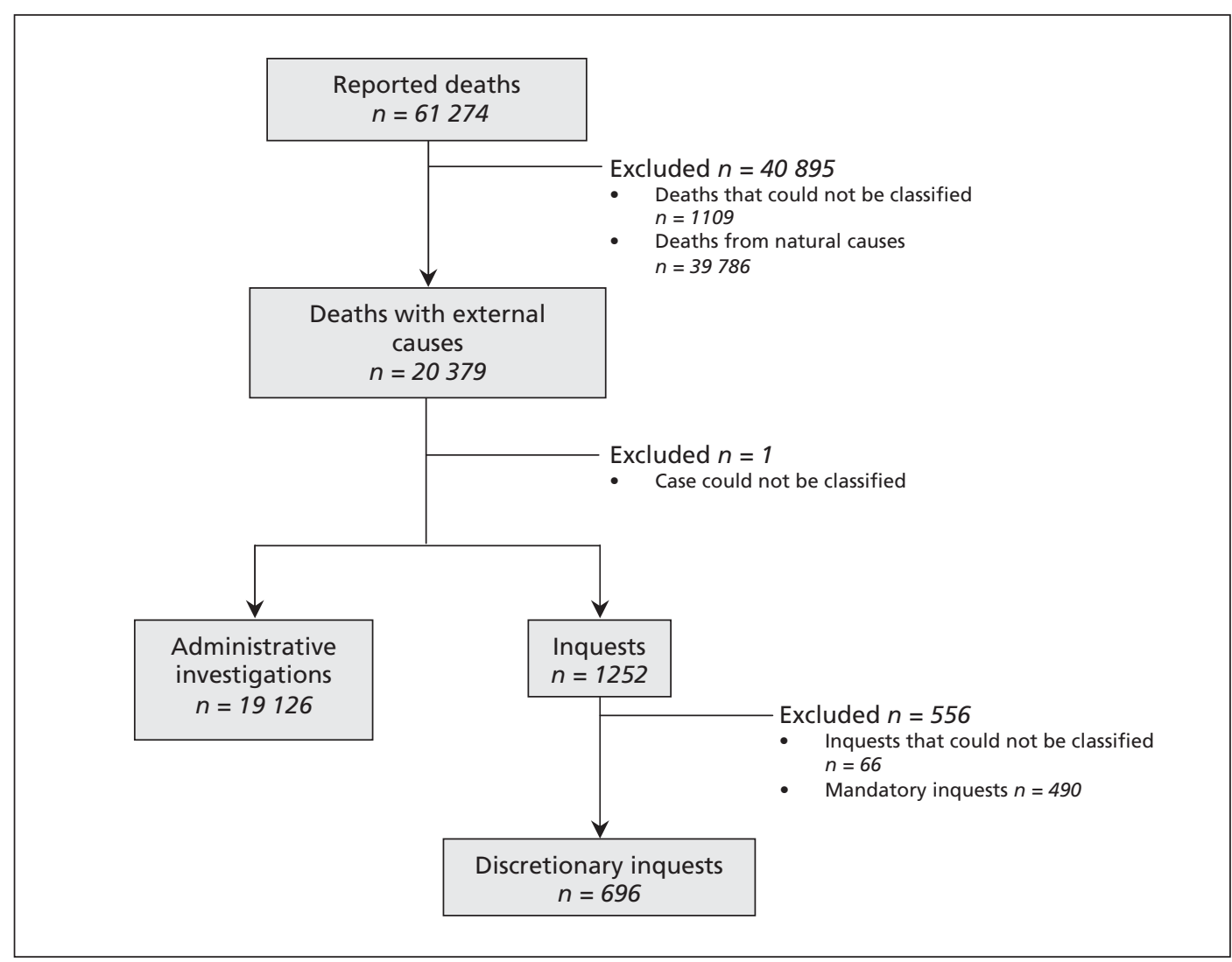

Figure 1: Selection of cases for the study sample. 
After eliminating mandatory inquests from the sample, the dataset included 696 discretionary inquests and 19126 administrative investigations. Table 2 shows a breakdown of the characteristics of the cases in each of these two forms of investigation.

\section{Outcomes}

In unadjusted analyses, age of the decedent and cause of death were both strongly associated with odds of inquest, but socioeconomic status was not (Table 2).

In adjusted analyses, the odds of a discretionary inquest decreased with age (Figure 2). Compared with deaths of people aged 45-64 years, deaths of children $(<18$ years of age) had more than twice the odds of discretionary inquest (OR 2.17, 95\% CI 1.54-3.06), whereas deaths of people aged 65 years or more had much lower odds of discretionary inquest (OR 0.38, 95\% CI 0.28-0.51). Compared with death by poisoning, suicides (OR $0.44,95 \%$ CI 0.30 0.65 ) and falls (OR 0.92, 95\% CI 0.44-1.90) had lower odds of discretionary inquest; deaths that were the result of complications during medical care (OR 12.83, 95\% CI 8.65-19.04), drowning, choking or suffocation (OR 5.12, 95\% CI 3.567.39), and transport accidents (OR 2.41, 95\% CI 1.75-3.33) had much higher odds.

Several other variables in the model had smaller but still significant associations. The odds that deaths of women would proceed to dis-

Table 2: Characteristics of the decedents included in the study sample by type of investigation into the death and the odds that the case would be sent to a discretionary inquest (part 1 of 2)

\begin{tabular}{|c|c|c|c|}
\hline Characteristic & $\begin{array}{c}\text { Discretionary } \\
\text { inquests, no. }(\%) \\
(n=696)\end{array}$ & $\begin{array}{c}\text { Administrative } \\
\text { investigations, } \\
\text { no. }(\%)^{*} \\
(n=19126)\end{array}$ & $\begin{array}{l}\text { Unadjusted } \\
\text { OR }(95 \% \mathrm{Cl})\end{array}$ \\
\hline \multicolumn{4}{|l|}{ Decedent } \\
\hline \multicolumn{4}{|l|}{ Sex } \\
\hline Male (reference) & $463(66.5)$ & $13813(72.2)$ & 1.00 \\
\hline Female & $233(33.5)$ & $5311(27.8)$ & $1.31(1.11-1.54)$ \\
\hline \multicolumn{4}{|l|}{ Age, yr } \\
\hline 45-64 (reference) & $166(23.9)$ & $4750(24.8)$ & 1.00 \\
\hline$<18$ & $134(19.3)$ & 1077 & $3.56(2.81-4.51)$ \\
\hline $18-44$ & $315(45.3)$ & $9144(47.8)$ & $0.99(0.81-1.19)$ \\
\hline$\geq 65$ & $81(11.6)$ & $4152(21.7)$ & $0.56(0.43-0.73)$ \\
\hline \multicolumn{4}{|l|}{ Marital status } \\
\hline $\begin{array}{l}\text { Divorced or separated } \\
\text { (reference) }\end{array}$ & $23 \quad(3.3)$ & $1699 \quad(8.9)$ & 1.00 \\
\hline Married $t$ & $268(38.5)$ & $6254(32.7)$ & $3.17(2.06-4.86)$ \\
\hline Never married & $221(31.8)$ & 3288 (17.2) & $4.97(3.22-7.66)$ \\
\hline Widowed & 10 & $466 \quad(2.4)$ & $1.59(0.75-3.35)$ \\
\hline Not known & $174(25.0)$ & 7419 (38.8) & $1.73(1.12-2.68)$ \\
\hline \multicolumn{4}{|l|}{ Employment status } \\
\hline Employed (reference) & $258(37.1)$ & $6583(34.4)$ & 1.00 \\
\hline Retired/pensioner & $127(18.2)$ & $5534(28.9)$ & $0.59(0.47-0.73)$ \\
\hline Unemployed & $92(13.2)$ & $2909(15.2)$ & $0.81(0.63-1.03)$ \\
\hline Student & $86(12.4)$ & $982 \quad(5.1)$ & $2.23(1.73-2.88)$ \\
\hline Other & $30 \quad(4.3)$ & $521 \quad(2.7)$ & $1.47(1.00-2.17)$ \\
\hline Child not at school & $45 \quad(6.5)$ & $331 \quad(1.7)$ & $3.47(2.48-4.85)$ \\
\hline Not known & $58 \quad(8.3)$ & $2266(11.8)$ & $0.65(0.49-0.87)$ \\
\hline \multicolumn{4}{|c|}{ Socioeconomic status, quintile $\ddagger$} \\
\hline 1 (poorest) (reference) & $137(19.7)$ & $3712(19.4)$ & 1.00 \\
\hline 2 & $108(15.5)$ & $2937(15.4)$ & $1.00(0.77-1.29)$ \\
\hline 3 & $137(19.7)$ & $3062(16.0)$ & $1.21(0.95-1.54)$ \\
\hline 4 & $173(24.9)$ & $4782(25.0)$ & $0.98(0.78-1.23)$ \\
\hline
\end{tabular}


cretionary inquests were slightly higher than those for deaths of men (OR 1.19, 95\% CI 1.00 1.41). Compared with people who were divorced or separated, the odds of a discretionary inquest were higher if the decedent was married (OR $2.14,95 \%$ CI 1.38-3.32) or had never married (OR 1.78, 95\% CI 1.10-2.87). None of the quintiles of socioeconomic status was a significant predictor of discretionary inquests (Appendix 2, available at www.cmaj.ca/lookup/suppl/doi:10.1503 /cmaj.110865/-/DC1).

\section{Sensitivity analyses}

We assessed the robustness of our findings in three ways. First, we included deaths by natural causes in the multivariable model (coded into a new and separate category for the variable "cause of death"). Second, to test whether Victoria, the jurisdiction with the highest number of cases, determined our results, we re-estimated the multivariable model within each jurisdiction. Neither of these alterations resulted in substantial changes to our main results.

Third, to test whether our findings may have been influenced by the clustering of cases among certain coroners who had preferences for or against inquests, we used a conditional logistic regression model on a subsample of cases (deaths from Victoria, 2000-2005), conditioning on the coroner responsible. This alternative analytical approach had minimal effect on the main findings, indicating that a "coroner effect" was

Table 2: Characteristics of the decedents included in the study sample by type of investigation into the death and the odds that the case would be sent to a discretionary inquest (part 2 of 2)

\begin{tabular}{|c|c|c|c|}
\hline Characteristic & $\begin{array}{l}\text { Discretionary } \\
\text { inquests, no. }(\%) \\
\quad(n=696)\end{array}$ & $\begin{array}{l}\text { Administrative } \\
\text { investigations, } \\
\text { no. }(\%)^{*} \\
(n=19126)\end{array}$ & $\begin{array}{l}\text { Unadjusted } \\
\text { OR }(95 \% \mathrm{CI})\end{array}$ \\
\hline \multicolumn{4}{|l|}{ Socioeconomic status, quintileł } \\
\hline 5 (richest) & $118(17.0)$ & $4202(22.0)$ & $0.76(0.59-0.98)$ \\
\hline \multicolumn{4}{|l|}{ Cause of death } \\
\hline Poisoning (reference) & $47 \quad(6.8)$ & $2348(12.3)$ & 1.00 \\
\hline Intentional self-harm & $61 \quad(8.8)$ & $6822(35.7)$ & $0.45(0.30-0.66)$ \\
\hline Transport & $266(38.2)$ & $4779(25.0)$ & $2.78(2.03-3.81)$ \\
\hline $\begin{array}{l}\text { Drowning, choking, } \\
\text { suffocation }\end{array}$ & $107(15.4)$ & $939 \quad(4.9)$ & $5.69(4.01-8.09)$ \\
\hline Falls & $9 \quad(1.3)$ & $895 \quad(4.7)$ & $0.50(0.25-1.03)$ \\
\hline Assault & $12 \quad(1.7)$ & $615 \quad(3.2)$ & $0.97(0.51-1.85)$ \\
\hline $\begin{array}{l}\text { Complications of medical } \\
\text { care }\end{array}$ & $86(12.4)$ & $434 \quad(2.3)$ & $9.90(6.84-14.33)$ \\
\hline Other & $85(12.2)$ & $1604 \quad(8.4)$ & $2.65(1.84-3.80)$ \\
\hline Not known & $23 \quad(3.3)$ & $690 \quad(3.6)$ & $1.67(1.00-2.76)$ \\
\hline \multicolumn{4}{|l|}{ Investigation } \\
\hline \multicolumn{4}{|l|}{ Year of notification } \\
\hline 2000/01 (reference) & $133(19.1)$ & $2726(14.3)$ & 1.00 \\
\hline $2002 / 03$ & $197(28.3)$ & $4520(23.6)$ & $0.89(0.71-1.12)$ \\
\hline $2004 / 05$ & $188(27.0)$ & $4890(25.6)$ & $0.79(0.63-0.99)$ \\
\hline $2006 / 07$ & $178(25.6)$ & $6990(36.5)$ & $0.52(0.42-0.66)$ \\
\hline \multicolumn{4}{|l|}{ Jurisdiction } \\
\hline Victoria (reference) & $470(67.5)$ & $10984(57.4)$ & 1.00 \\
\hline South Australia & $72(10.3)$ & 3193 (16.7) & $0.53(0.41-0.68)$ \\
\hline Queensland & $50 \quad(7.2)$ & $2400(12.5)$ & $0.49(0.36-0.65)$ \\
\hline Tasmania & $51 \quad(7.3)$ & $1472 \quad(7.7)$ & $0.81(0.60-1.09)$ \\
\hline Northern Territory & $53 \quad(7.6)$ & $1077 \quad(5.6)$ & $1.15(0.86-1.54)$ \\
\hline \multicolumn{4}{|c|}{$\begin{array}{l}\text { Note: } \mathrm{Cl}=\text { confidence interval, } \mathrm{OR}=\text { odds ratio } \\
\text { *Excludes two cases in which sex was not known and three cases in which age was not known. } \\
\text { tIncludes de facto relationships (e.g., common-law marriages). } \\
\text { fExcludes } 454 \text { cases ( } 23 \text { inquests and } 431 \text { administrative investigations) in which socioeconomic status could not be imputed. }\end{array}$} \\
\hline
\end{tabular}


unlikely to explain the pattern of inquests we saw. This result resonates with anecdotal reports from several of the jurisdictions we studied that suggested the decisions about which cases to take to inquest and which coroners will preside over those inquests are frequently made collaboratively, at the court level, rather than by individual coroners acting independently.

Further details of our sensitivity analyses are available in Appendix 1.

\section{Interpretation}

\section{Main findings}

Based on this analysis of a large sample of cases from five Australian jurisdictions spanning seven and one-half years, we found that about 1 in 20 deaths went to inquest. Most of these inquests $(55.6 \%)$ were held at the coroner's discretion. Coroners were disproportionately likely to hold inquests for deaths involving children, deaths due to medical complications and deaths resulting from transport accidents. However, coroners were disproportionately unlikely to hold inquests for deaths due to suicide and deaths among the elderly ( $\geq 65$ years of age).

\section{Comparison with other studies}

Although Anglo-American justice systems prize transparency and openness, the process of inves- tigating deaths remains opaque to the general public, ${ }^{1,2,21}$ with one exception: inquests. Inquests, and the publicity surrounding them, ${ }^{3}$ shape public knowledge and understanding of death, particularly how and why unnatural deaths occur. The entire picture is framed, however, by choices made behind the scenes as to which deaths should proceed to inquest. Our analysis shows that those choices tend to emphasize certain types of death and de-emphasize others.

The paucity of research examining how coroners function and make decisions may result from the absence of suitable sources of data, the lack of a public health tradition in most coroners courts, and the traditional focus of courts and legal scholars on case-by-case analyses, as opposed to empirical studies at the population level. ${ }^{22}$

What explains the significant associations we found between the characteristics of cases and discretionary inquests? Considered as a group, the positive and negative predictors suggest three considerations may factor heavily in coroners' decisions about whether to take a case to inquest: preventability of the death, aberrance and the preferences of the decedent's family.

Australian coroners, like their Canadian counterparts, have the power to make recommendations to improve public health and safety, and inquests are the standard springboard for such

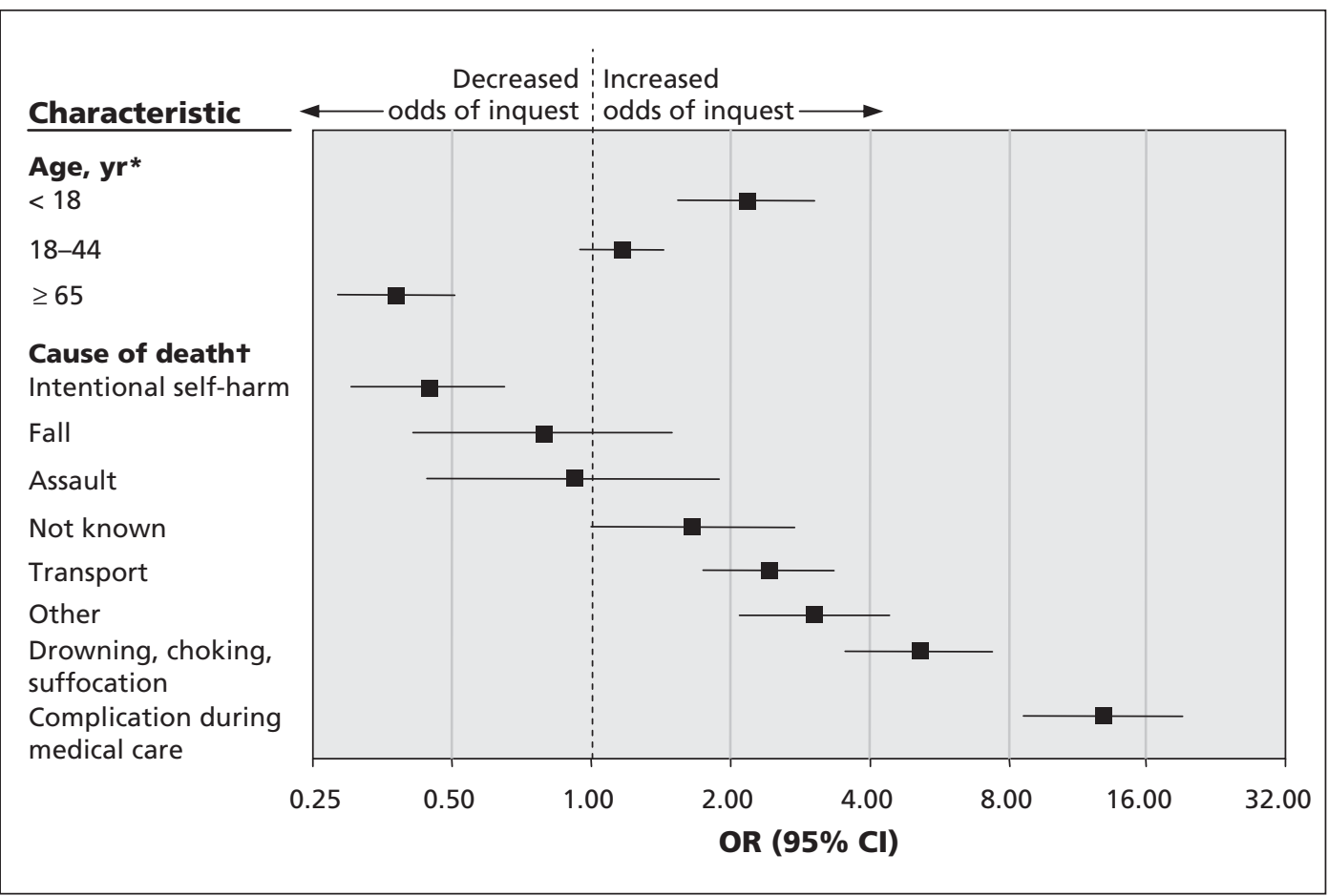

Figure 2: Factors predicting coroners' decisions to hold discretionary inquests. The multivariable logistic regression model was adjusted for jurisdiction, year and their interaction, as well as the sex, socioeconomic status and marital status of the decedent. $\mathrm{Cl}=$ confidence interval, $\mathrm{OR}=$ odds ratio. *Compared with reference group (people aged 45-54 yr). +Compared with reference group (deaths by poisoning). 
recommendations. Consequently, in choosing cases for inquests, coroners may also be choosing opportunities to make recommendations for prevention. This makes perceived preventability an important consideration.

It is plausible that deaths due to transport crashes and drowning - two external causes of death that were strong predictors of discretionary inquests in our sample - would rank highly in any hierarchy of perceived preventability. ${ }^{23,24}$ The events that lead to such deaths are often observable and amenable to causal analysis. In addition, there is a solid base of evidence from research on preventing injuries from which coroners can draw when formulating their findings and recommendations. In contrast, suicide, the cause of death least likely to proceed to discretionary inquest, may be perceived as a much more challenging target for prevention. The causal chain can be difficult to unravel, complex questions concerning access to mental health services may arise and, unfortunately, suicide research has yielded few effective prevention strategies.

Aberrance refers to deaths that exceed the bounds of reasonable expectations and are deeply shocking - not only to the friends and family of the decedent, but to the wider community. Deaths resulting from complications during medical care, which had the highest rates of discretionary inquest, often fit this description. These deaths occur under circumstances in which families expect loved ones to be helped, rather than harmed. Similarly, deaths among children and young people, which also had high rates of discretionary inquest, are considered particularly tragic, and the impetus to hold inquests for these deaths may be considerable. In such cases, inquests can provide families with the opportunity to receive explanations for what happened and may be seen as an act of closure.

In deciding whether to hold an inquest, Australian coroners typically consult with family members to learn their wishes. For some types of death, such as suicide (a negative predictor in our model), families may prefer to avoid the public attention that inquests provoke. For other types of death, families may wish to highlight the event. Previous research shows that families who experience the serious medical injury of a loved one are often motivated to pursue medicolegal action by a desire to understand what happened and ensure it does not happen to anyone else. ${ }^{25,26}$

An alternative explanation for our findings is that coroners' courts may use internal rules or guidelines in assessing cases that are candidates for inquest; if this happened, the patterns of inquest we saw may simply reflect the content of such decision-making tools. Based on the inquiries made in the five jurisdictions included in our analyses, we determined that two use internal guidelines. However, a review of these guidelines shows that they are nonprescriptive; they mention only general factors to consider in selecting cases for inquest, such as the existence of substantial factual uncertainties or concerns for public health and safety. ${ }^{27,28}$ As such, the guidelines could not plausibly constrain coroners' discretion to an extent that would explain our findings. Nonetheless, these types of guidelines are not formally published, so it is possible that other jurisdictions may have used them at some stage and not reported doing so.

\section{Limitations}

Our study had several limitations. We had to exclude data from several years for two states. In addition, our findings may not be generalizable to Australian jurisdictions not included in our sample, nor to other countries. The wide international variation evident in inquest rates (Table 1) raises further questions as to generalizability because it suggests substantially different statutory rules and discretionary choices across countries.

A further limitation is the crudeness of the SEIFA measure of socioeconomic status owing to its area-level derivation.

Finally, the covariates available for analysis are limited and, as our earlier discussion suggests, are best interpreted as markers for considerations that drive coroners' decision-making about selecting cases for inquest. Ideally, this type of analysis would directly test characteristics such as preventability and aberrance, but these concepts are difficult to define and would be hard to measure at the caseload level.

\section{Conclusion}

The public's knowledge of what coroners do, and the crux of coroners' contributions to advancing public health and safety, comes from inquests. Therefore, understanding which types of deaths proceed to inquest is pivotal to understanding how coroners function. We found clear evidence of selection effects. Further research is needed to investigate whether similar patterns exist outside of Australia. The implications of emphasizing certain types of deaths through inquests, and de-emphasizing others, should also be assessed. As governments around the world look to coroners to function as proactive agents of public health, not merely as passive investigators of death, ${ }^{1,27,29}$ there is a growing need to demystify coroners' functions. 


\section{References}

1. Luce $\mathrm{T}$ (Chair). Death certification in England, Wales and Northern Ireland - the report of a fundamental review 2003 Command Paper: CM 5831. London (UK): The Stationery Office; 2003. Available: www.archive2.official-documents .co.uk/document/cm58/5831/5831.htm (accessed 2011 Dec. 22).

2. Freckelton I, Ranson D. Death investigation and the coroner's inquest. Melbourne (Australia): Oxford University Press; 2006.

3. Waterford J. The media and inquests. In: Selby H, editor. The inquest handbook. Sydney (Australia): The Federation Press; 1998.

4. Statistics on deaths reported to coroners: England and Wales, 2009. Ministry of Justice; 2010. Available: www.justice.gov.uk /publications/docs/coroners-stats-deaths-2009.pdf (accessed 2012 Jan. 12)

5. Annual report. Burnarby (BC): BC Coroners Service; 2004 Available: www.pssg.gov.bc.ca/coroners/publications/docs /annualreport2004.pdf (accessed 2012 Jan. 6).

6. Annual report. Burnarby (BC): BC Coroners Service; 2008. Available: www.pssg.gov.bc.ca/coroners/publications/docs /annualreport2008.pdf (accessed 2012 Jan. 6).

7. The Shipman Inquiry. Third report: death certification and investigation of deaths by coroners. Command Paper: CM 5854. London (UK): The Stationery Office; 2003.

8. Coroners Act. 2009 (NSW)

9. Coroners Act. 2008 (Vic).
10. Coroners Act 2003 (Qld)

11. Coroners Act. 1996 (WA).

12. Coroners Act. 2003 (SA)

13. Coroners Act 1995 (Tas)

14. Coroners Act. 1993 (NT).

15. Coroners Act. 1997 (ACT)

16. National Coronial Information System coding manual and user guide. Version 4. Melbourne (Australia): National Coronial Information System; 2010. Available: www.ncis.org.au/web _pages/user_publications.htm\#a12 (accessed 2012 Jan. 12).

17. Data dictionary of the National Coronial Information System Version 3. Melbourne (Australia): National Coronial Information System; 2010. Available: www.ncis.org.au/web_pages /user_publications.htm\#a11 (accessed 2012 Jan. 12).

18. Daking L, Dodds L. ICD-10 mortality coding and the NCIS: a comparative study. HIM J 2007;36:11-23.

19. Driscoll TR, Henley G, Harrison JE. The National Coroners Information System as an information tool for injury surveillance. Australian Institute of Health and Welfare (Australia); 2003.

20. Hosmer D, Lemeshow S. Applied logistic regression. New York (NY): Wiley; 2000. p. 142-202.

21. Committee for the Workshop on the Medicolegal Death Investigation System. Medicolegal death investigation system: workshop summary. Washington (DC): National Academies Press; 2003.

22. Studdert DM, Cordner SM. Impact of coronial investigations on manner and cause of death determinations in Australia, 20002007. Med J Aust 2010;192:444-7.

23. Mock C, Quansah R, Krishnan R, et al. Strengthening the prevention and care of injuries worldwide. Lancet 2004;363:2172-9.

24. Franklin RC, Scarr JP, Pearn JH. Reducing drowning deaths: the continued challenge of immersion fatalities in Australia. Med J Aust 2010;192:123-6.

25. Vincent C, Phillips A, Young M. Why do people sue doctors? A study of patients and relatives taking legal action. Lancet 1994; 343:1609-13.

26. Bismark M, Dauer E, Paterson R, et al. Accountability sought by patients following adverse events from medical care: the New Zealand experience. CMAJ 2006; 175:889-94

27. Victorian Parliament Law Reform Committee. Final report. Review of the Coroner' Act 1985. Melbourne (Australia): The Committee; 2006.

28. Coroners Court of Queensland. When should an inquest be held? [internal document].

29. Freckelton I. Reforming coronership: international perspective and contemporary developments. J Law Med 2008;16:379-92.

Affiliations: From the Melbourne School of Population Health (Walter, Spittal), University of Melbourne, Parkville; Accident Research Centre (Bugeja), Monash University, Clayton; and Melbourne School of Population Health and Melbourne Law School (Studdert), University of Melbourne, Parkville, Australia

Contributors: David Studdert and Simon Walter conceived the study and drafted the manuscript. Simon Walter, Matthew Spittal and David Studdert designed the study. Simon Walter and Lyndal Bugeja constructed the dataset used in this study. Simon Walter and David Studdert had full access to the data and take responsibility for its accuracy and analysis. All authors critically revised the manuscript for important intellectual content and approved the final version submitted for publication.

Funding: This work was supported by a Federation Fellowship (FF0668632 to David Studdert) from the Australian Research Council.

Acknowledgements: The authors thank Michael Barnes, Stephen Cordner and Jane Pirkis for providing helpful comments on an earlier draft of the manuscript. 